\title{
Industrial construction of the late XIX-early $X X$ centuries: barracks for workers of the Moscow region manufactories
}

\author{
Tatyana Shamaeva* \\ National Research Moscow State University of Civil Engineering (NRU MGSU), 129337, Moscow, \\ Russia
}

\begin{abstract}
In this paper, the objects of research are barracks for workers of industrial manufactories of the late XIX - early XX centuries, situated in the Moscow region.

Recommendations for the functional purpose of these buildings:

1. Residential function with apartments of 1 comfort category, improved design; colivings.

2. Guesthouses, hotels.

2. Public function: offices, exhibitions, museums, medical institutions, food facilities, trade, beauty salons, hairdressers, household services and minor repairs can be located on the first floors of the building. Leisure centers for different age groups, clubs for children and young people, fitness centers.
\end{abstract}

\section{Introduction}

This paper is devoted to the architectural and urban planning analysis of barracks for workers of industrial manufactories. The boundaries of the study were the territorial affiliation to the Moscow region and the years of construction of the barracks-the end of the XIX century - the beginning of the XX century. These buildings belong to the industrial architectural heritage. There is a problem of their preservation and use in the future. The paper analyzes the possible trends in the use of the studied objects in the future.

\subsection{Relevance of the topic}

The stage of formation of the industry occurred at the end of the XIX century - the beginning of the XX century (1760-early 1910) and is characterized by the industrial revolution, as well as the origination of functional industrial architecture [1]. Barracks for workers were built at enterprises for single and family workers. The living conditions were extremely difficult. The buildings of the barracks are divided into blocks for various purposes, including blocks for living with common rooms and rooms for families. The area of rooms for families is $12-14$ sq. m. mainly for 2 families. Large common rooms for up to

* Corresponding author: ShamaevaTV@yandex.ru 
40-50 people with an area of up to 70-100 sq. m. [2-5]. The space-planning type of the building is corridor. Separate blocks of sanitary facilities with bathrooms and showers, food blocks - canteens.

Today, "red" brick barracks exist in many cities of the Moscow region, due to the fact that at the end of the XIX - early XX century, these cities were built and developed around manufactories. It was the manufactories and factories that became the city-forming elements. And the barracks of those years still exist today. These buildings need not just major repairs, reconstruction, but a complex process - revitalization (from Lat. "return to life"), that is, in the reconstruction and revitalization of buildings in the context of urban space. The main principle of revitalization is to open up new opportunities for old territories and buildings. In the process of revitalization, an integrated approach is used to preserve the uniqueness, authenticity, identity and historical resources of the urban environment [6].

In our time, there are successful examples of revitalization, reconstruction of industrial facilities. These objects, as a rule, represent a complex of objects, former production enterprises. Proper attention to the theme of the barracks of the late XIX - early XX century, as separate objects located in the existing urban development, was not paid.

\section{Materials and methods}

The analysis of 10 objects was carried out. To analyze the architectural and urban appearance of buildings, objects were selected according to the following criteria:

- construction site - Russia, Moscow region;

- the original function of the buildings - barracks for housing of workers at factories, manufactories of the late XIX - early XX century;

- the period of construction of barracks - in the end of XIX - beginning of XX century, pre-revolutionary period;

- the number of employees of the enterprise is about 1000 workers or more.

Modern architectural and urban appearanceof working barracks is presented in Table 1. Places of the selected objects in the territory of the Moscow region is shown in Figure 1. The object numbers in the figure correspond to the numbers of objects in the table.

The aim of the work is to analyze the architectural and urban appearance of the barracks for workers and to solve the following tasks:

- to identify the characteristic features of space-planning solutions of barracks in the city structure;

- to analyze the current state of the objects, from the following positions: external appearance, functional use, improvement of the territory;

- to identify the positive aspects, possible trends in the use of the studied objects in the future.

We offer recommendations on the functional purpose of these buildings after reconstruction and revitalization.

Scientific significance. The paper raises the question of the future fate of this typological type of buildings. An attempt was made to predict the options for further development of events for these objects. Promising directions for the appropriate use of the studied objects are proposed.

The barracks considered and studied in the course of the analysis are located in different cities of the Moscow region. Each object consists of a different number of buildings and sections. The number of buildings or sections of a single object is from 1 to 6 . The total number of buildings analyzed in the paper is about 26 buildings. 


\section{Results and discussion}

The analysis of the current state of the objects led to the following results. The buildings were built between 1880 and 1913. The barracks were built for single workers and families and, still, more than 100 years later, most of them are inhabited by people.

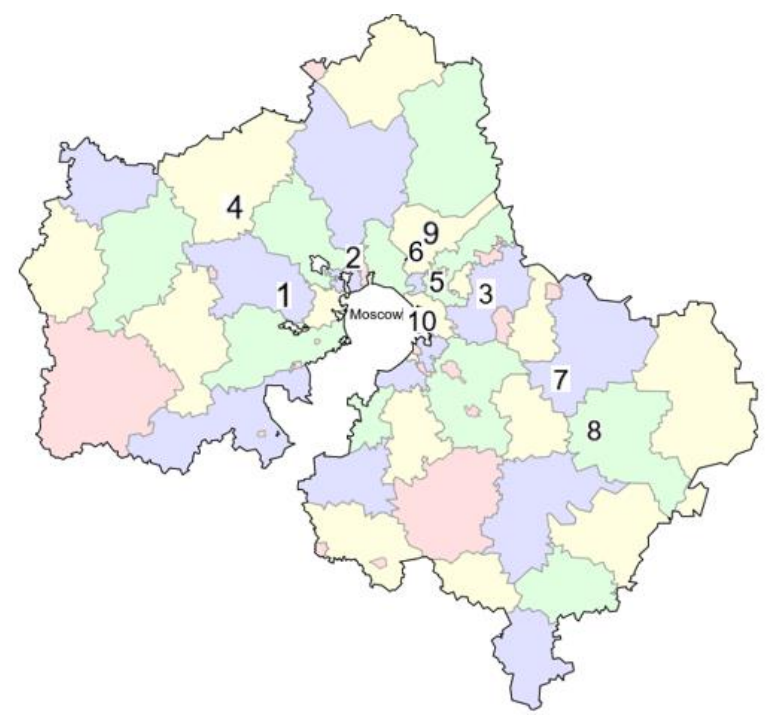

Fig. 1. Map of the location of objects in the Moscow region.

\subsection{Characteristic features of space-planning solutions of these buildings:}

\section{By function:}

- Residential function: residential apartments, dormitories - 70\%; public function - $30 \%$. This is a hospital, a police building, a club, a museum, offices, multifunctional buildings (shopping function, catering);

The number of sectionsvaried and depended not only on the number of workers of the enterprise, but also on the principle of settlement. Individual barracks buildings or sections of buildings could be designed for single people, for families, as well as for "family", but not married, which was condemned by the society of the time, and they were given separate housing for living.

Number of floors of buildings:

- from 2to 5 floors;

- most of the barracks buildings are 4-5 storeys high.

Planning type:

- corridor.

\subsection{Results of the analysis of the architectural and urban-planning appearance}

By physical condition as of today:

- $85 \%$ of the buildings studied are in a terrible state. Reconstruction, major repairs, restoration are required. This applies to facades, structures, planning solutions, etc. 
$-15 \%$ are currently empty, the residents are settled. The further fate of the buildings is not known. Only two of the buildings considered are waiting for the promised reconstruction. Unfortunately, several buildings were already demolished.

Facades, volumes, details of facades. The loss of some elements of facades, the reconstruction of entrance groups, "alien" extensions to buildings, the replacement of windows with a different arrangement of frames and bindings, unfortunately, this applies to all objects without exception. One case of the device of the ventilated facade on top of the existing one was revealed, which completely changed the original appearance of the barracks building.

In the urban planning situation, the considered barracks are located outside the territory of the enterprise (100\%). In 50\% - the buildings of the barracks continue to be dominant in the urban situation of the central part of the city. The remaining $50 \%$ of the barracks are located in residential areas, on the outskirts of the city, but they are also the centers of neighborhoods and significant elements of streets in the current urban development situation.

There is no improvement of the adjacent territory of the object in all the studied situations $(100 \%)$. There is only an existing street network with driveways and sidewalks. No parking for cars, no yard spaces, recreation areas, etc.

Table 1 Objects for analysis. Modern architectural and urban planning look of the barracks for workers of the late 19th-early 20th centuries in Moscow region

\begin{tabular}{|c|c|c|}
\hline № & $\begin{array}{l}\text { Address, company name, } \\
\text { year of construction, photo. } \\
\text { Number of factory workers }\end{array}$ & $\begin{array}{l}\text { Characteristics of the architectural and urban } \\
\text { look. } \\
\text { Year of construction of the barracks. The } \\
\text { number of buildings and houses. Current } \\
\text { state. }\end{array}$ \\
\hline 1 & $\begin{array}{l}\text { Dedovsk, Istra, Cotton } \\
\text { Manufactory, } 1912 . \\
\text { 1500-1800 workers }\end{array}$ & $\begin{array}{l}\text { 1913 } \\
\text { - } 1 \text { building of } 3 \text { sections: } 1 \mathrm{~h} \text {. - for families, } 1 \\
\text { h. - for singles, } 1 \mathrm{~h} \text {. - sanitary facilities for } \\
\text { general use. } \\
\text { - } 4 \text { floors with a basement } \\
\text { - Current state: since } 1990 \mathrm{~s}-\text { small apartments } \\
\text { with shower, hostel for nonresidents; in the } 1 \mathrm{st} \\
\text { building on the } 1 \text { st floor: pharmacies, shops. } \\
\text { - The center of the city, the dominant of the } \\
\text { city. } \\
\text { - City-form in element to date } \\
\text { - Condition: requires reconstruction, repair } \\
\text { - Territory improvement: no. }\end{array}$ \\
\hline 2 & $\begin{array}{l}\text { Lobnya, Cotton Spinning } \\
\text { Mill, 1850. } 2000 \text { workers }\end{array}$ & $\begin{array}{l}\text { 1879 } \\
\text { - } 2 \text { buildings, each consisting of } 3 \text { sections: for } \\
\text { single and family (room for } 2 \text { families). } \\
\text { - } 4-5 \text { floors } \\
\text { - Current state: residential apartments. } \\
\text { - Territory improvement: no. } \\
\text { - The outskirts of the city. The center of the } \\
\text { block with a new residential development } \\
\text { - The city-forming element of a block or } \\
\text { neighborhood. } \\
\text { - Condition: requires reconstruction, repair }\end{array}$ \\
\hline
\end{tabular}




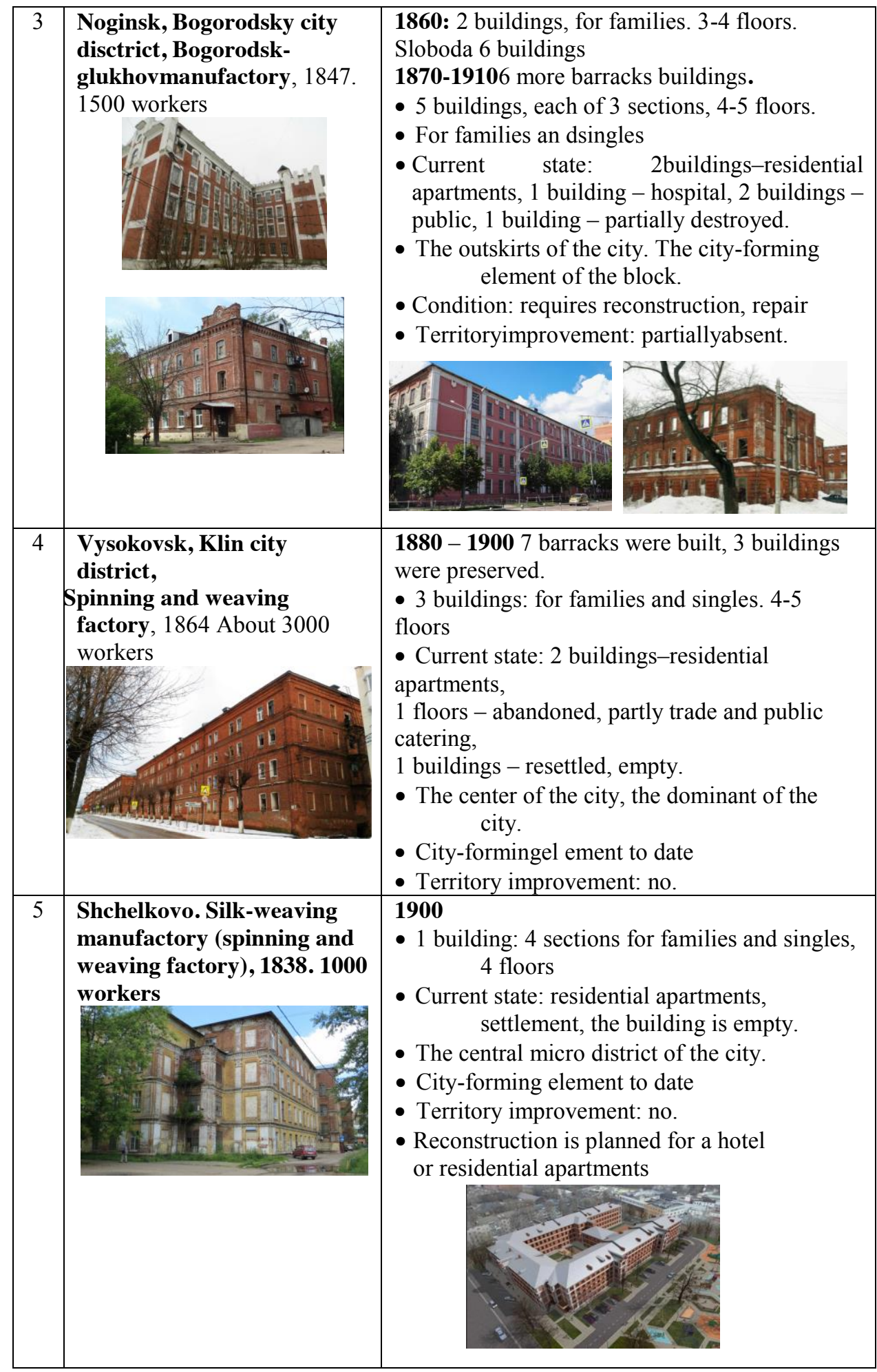




\begin{tabular}{|c|c|c|}
\hline 6 & $\begin{array}{l}\text { - Pushkino, } \\
\text { Kudrinkamicrodistrict, 1830- } \\
\text { 1873. About } 900 \text { workers } \\
\text { Clothmanufactory. }\end{array}$ & $\begin{array}{l}\text { 1908 } \\
\text { - } 2 \text { buildings: Dormitory houses-bedroom. } 2 \\
\text { floors } \\
\text { - Current condition: } 1 \text { building-residential, } 1 \\
\text { building-eviction, in an abandoned state, } \\
\text { - The city centre. City-forming element } \\
\text { - Condition: } 1 \text { building-abandoned, } 1 \text { building- } \\
\text { requires reconstruction, repair. } \\
\text { - Territory improvement: no. }\end{array}$ \\
\hline 7 & $\begin{array}{l}\text { Likino-Dulevo, Orekhovo- } \\
\text { Zuevo, Likinsk } \\
\text { manufactory, } 1870 \text {. } \\
\text { - About } 3000 \text { workers }\end{array}$ & $\begin{array}{l}1905 \\
\text { - } 4 \text { buildings, eachwith 2-3 sections: } \\
\text { Dorm buildings-bedrooms. 3-4 floors } \\
\text { - Current state: requires reconstruction, repair. } \\
1 \text { building-residential, Ground floor local history } \\
\text { museum, police; renovated; } 2 \text { buildings- } \\
\text { residential, } 1 \text { building-commercial. } \\
\text { Partiallyrenovated, partiallyabandoned. } \\
\text { - Central street of the city. City-formingelement } \\
\text { - Territoryimprovement: no. }\end{array}$ \\
\hline 8 & $\begin{array}{l}\text { Egoryevsk, Textile } \\
\text { manufactory (cotton mill, } \\
\text { spinning, weaving and } \\
\text { finishing mill), } \\
\text { 1845. } 3000 \text { workers }\end{array}$ & $\begin{array}{l}\text { 19012 buildings, residential. 2-3 floors } \\
\text { - Current state: Buildings - residential. } \\
\text { - Central district of the city. City-form } \\
\text { ingelement } \\
\text { - Condition: requires reconstruction, repair. } \\
\text { - Territory improvement: no. }\end{array}$ \\
\hline
\end{tabular}




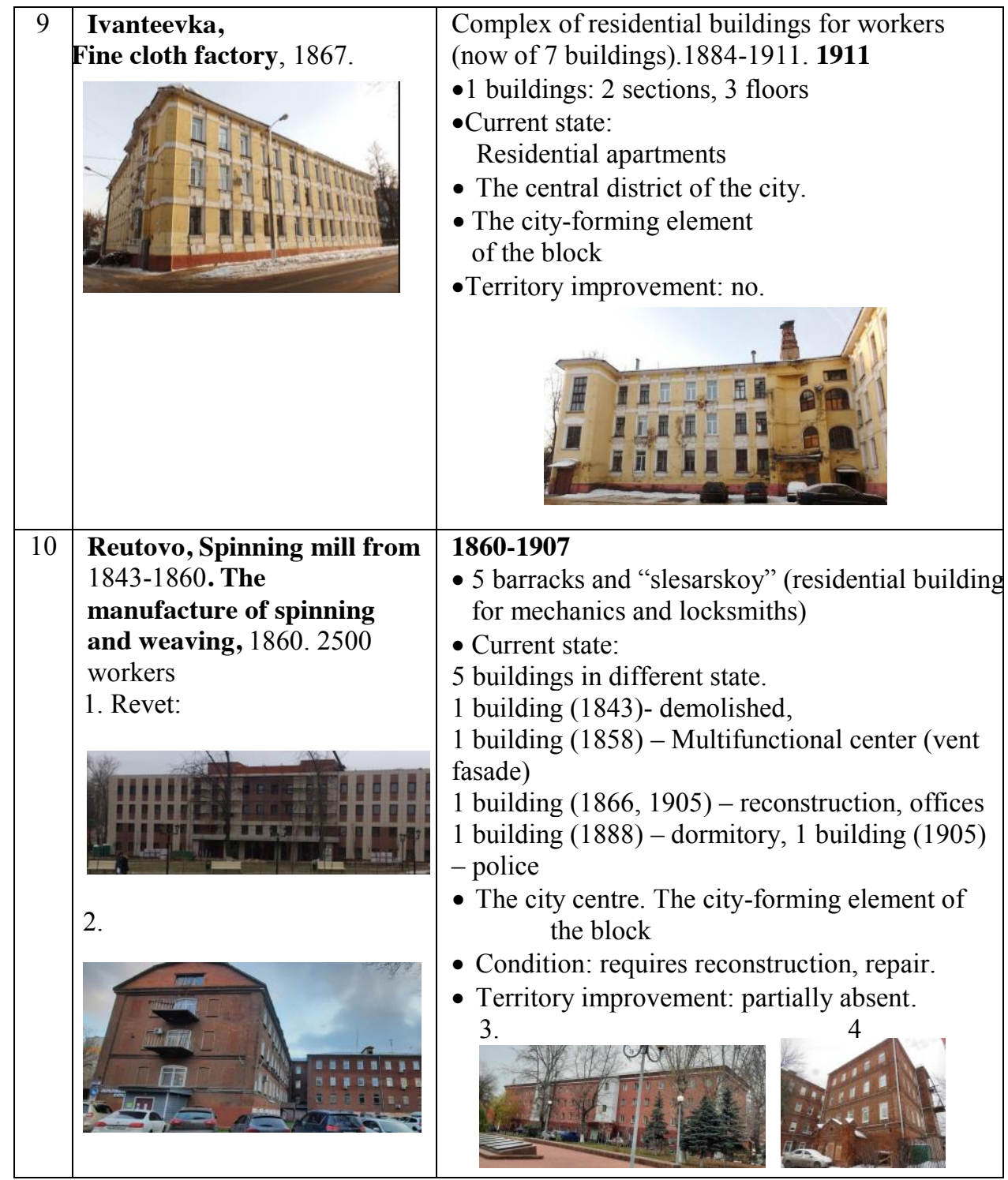

We will determine the trends in the development of the situation in the future for the objects under study. It is possible to develop in several ways. Measures to modernize the historical center include: restoration, reconstruction or demolition of old buildings, construction of new buildings that often do not harmonize with the environment [6]. The first option is the renovation of the territory with the demolition of buildings of the late XIX - early XX centuries, followed by the construction of this territory. Land plots in the central part of the city are undoubtedly of interest to investors for new construction, usually residential development [7]. The demand for comfortable housing has always been very high, which is more cost-effective: new construction or reconstruction of residential buildings? [8]. The opinion that it is easier to build a new building than to reconstruct or rebuild an existing building is mostly true. Less than $40 \%$ of the considered objects have the status of a monument of architecture, culture or history. But even this status does not guarantee the safety of the building in the future, as the status may be revoked over time. 
For example, as it happened in Kazan, as a result of which, the barracks were demolished and construction of a residential complex began on the vacated territory. The second option is the reconstruction of the building. Unfortunately, the buildings are not in a hurry to reconstruct. The barracks are under the jurisdiction of the city, the administration, and the city, as a rule, does not have the funds for the process of relocation of residents and further reconstruction. Reconstruction of buildings may include the following complex of works. The load-bearing elements of the building, such as walls, are designed for a long service life. The thickness of the brick walls is about $740-850 \mathrm{~mm}$. In most cases, reconstruction is the restoration of facades: removal of the growth layer of the earth, from the germination of herbaceous plants and moss, restoration and renovation of the facade decor, and partial strengthening of masonry walls; partial or complete replacement of roof constructions, in some cases, replacement of the slab. This is due to the fact that the roof and ceiling structures could be made of wood. Complete replacement of engineering services. And the last important point is the redevelopment of the barracks, the installation of partitions for a new function. The dismantling of the extensions. Reconstruction of staircase elements, replacement of windows and doors. Performing landscaping of the surrounding area. This is the main work on the reconstruction of the barracks. The third option - the most humane according to the author of the paper - is the revitalization of buildings in the urban environment. A complex of works on the reconstruction of buildings, changing or improving functional and planning solutions with modern requirements, taking into account the directions of the city development, development of measures for the improvement of the territory in the context of the urban situation. The priority directions of solving the problem of long-term development of outdated development areas are a comprehensive solution to the problem of outdated housing stock of the city [9].

Recommendations for the functional purpose of these buildings after reconstruction.

The architectural and urban look of buildings, the placement of objects in the city suggest that the future use of buildings will be for the following functions.

1. For accommodation with apartments of the 1st category of comfort. Housing will become "prestigious" according to several criteria: placement in the city structure and a new "improved" layout of apartments. These residential buildings are located in the central districts of the city. The structural wall system of the building (the location of the internal load-bearing walls, the width of the building) allows designing apartments according to modern requirements. Barracks are possible to be adapted a modern type of living coliving.

2. For public functions: offices, administrative buildings, which implies a corridor layout; exhibition spaces and museums with enfilade layout and partially free floor layout; polyclinics, hospitals-corridor type. The functions of food, trade, beauty salons, hairdressers, household services and minor repairs can be located on the first floors of the building. Leisure centers for different age groups of the population, clubs for children and youth, fitness centers, are also in demand and needed by the population and can be in these buildings. One of the options may be to adapt the building to accommodate a hotel with the layout of a typical corridor-type floor.

The planning structures of the barracks buildings after reconstruction may be as follows:

- corridor type;

- enfilade plan structure;

- partially "free" layout;

- mixed, a combination of the above types.

We will indicate the advantages and positive aspects of the use of the studied objects after reconstruction. After the reconstruction, the city gets two types of buildings: these are 
residential buildings with prestigious apartments of increased comfort or public buildings, as centers of attraction for the population, with social or leisure-entertainment, educational centers, as well as for the development of tourist destinations - hotels, guesthouses. These functions are relevant for the development of small and medium-sized cities in the Moscow Region.

The architecture of "red brick" with decorative elements, windows, "belts" can be used and correspond to any of the listed functions. An important aspect is the preservation of the historical architectural and urban look of buildings laid down in the late XIX - early XX century, which are still, in most cases, the dominant central districts in the cities of the Moscow region.

\section{Conclusion}

Today we are responsible for preserving the memory of our history, of our past. Barracks for workers of the pre-revolutionary period are not just buildings that are more than 100 years old; they are living participants in the events of those years, with their own history about a bygone era. Examples of industrial architecture of the late XIX- early XX centuries can bring an individual flavor to a modern city. These buildings, after reconstruction and revitalization, can gain a "second life" and become attractive and in demand in today's modern conditions. The topic of the paper undoubtedly deserves attention. Caring for our past is one of the tasks of the modern generation.

\section{References}

1. V.I. Vershinin, Evolution of industrial architecture, Textbook (Architecture-S, Moscow, 2007).

2. S.Yu. Mamaev, Dedovsk. The age of change (Pero Publishing House, 2015).

3. Central Historical Archive of Moscow (CHAM): F. 54. Op. 166. D 466. Construction of the barracks at the Dedovsk Manufactory, 1912

4. E.N. Podyapolskaya, Monuments of architecture of the Moscow region 1999: illustrated scientific catalog, Cultural Com. of Moscow region Center of Scientific, Restoration and Project Workshops of the Ministry of Culture of the Russian Federation Moscow, Stroyizdat, 24

5. "In the kingdom of the Morozovs. Materials on the history of the Glukhovskaya factory". Publication "Bogorodsky Krai" 1928 4-5, 16 from the website of Bogorodsky Regional Studies. URL: https://bogorodsk-noginsk.ru

6. A. Kononowicz, Construction and Architecture 17 (1), 77-83 (2018).

7. A.A. Barabanov Eco-potential 3-4, 237-248 (2013).

8. O.V. Petreneva, V.O. Pikuleva, Bulletin of MSCU 3, 122-134 (2016).

9. V.V. Kovalov, S.P. Bronevytsky, Ye.V. Protasova, Bulletin of Prydniprovska State Academy of Civil Engineering and Architecture 1, 19-32 (2019). 